\title{
Cruces textuales del discurso bíblico y el discurso político en el género columna: claves para su procesamiento*
}

\author{
Text Intersections between the Biblical Discourse and the Political Discourse in the Genre of Opinion Pieces: Clues \\ to Process \\ Cruzamentos textuais do discurso bíblico e o discurso político no género coluna: chaves para seu processamento
}

\author{
Federico Pastene Labrin ${ }^{\text {a }}$ \\ Universidad del Bio-Bio, Chile \\ fpastene@ubiobio.cl \\ ORCID: http://orcid.org/0000-0003-2642-5157
}

DOI: https://doi.org/10.11144/Javeriana.syp37-72.ctdb

Redalyc: http://www.redalyc.org/articulo.oa? $\mathrm{id}=86057225003$

Fecha de recepción: 10 Marzo 2017

Fecha de aprobación: 17 Abril 2018

\section{Resumen:}

Este artículo aborda algunos cruces textuales del discurso bíblico y político producidos en el género discursivo periodístico de opinión 'Columna', a partir de un hecho noticioso y político contingente como el 'Caso Caval', que involucra a la familia presidencial chilena, generando variados sentidos. La metodología consiste en el análisis textual de una columna publicada en un diario de circulación nacional en Chile, titulada "El martirio del hijo", desde una perspectiva discursiva y contextual. Entre los resultados obtenidos del análisis se destaca: i. el lector en su procesamiento debe activar diversos intertextos, reflejo de un complejo entramado de configuración textual que apela y desafía, sin duda, la competencia cultural del sujeto receptor; ii. éste cruce de textos presente en la columna, se constituye en una estrategia discursiva mediante la cual el sujeto enunciador evalúa crítica e irónicamente un hecho político donde se confronta el poder, la opinión pública y la justicia. En suma, el empleo de estos procedimientos enriquece la textualidad y genericidad de un texto periodístico de opinión.

Palabras clave: columna, discurso bíblico, discurso político, intertextualidad, recepción.

\section{Abstract:}

This article addresses some text intersections between the Biblical and political discourses taking place in the journalistic discursive genre of 'Opinion Piece', based on a contingent political and news event like the "Caval Case", which involved the Chilean presidential family and brought about diverse understandings. The methodology consists in the text analysis of an opinion piece published in a Chilean national newspaper under a discursive and contextual approach. The piece was titled The Son's Sacrifice. The noticeable results from the analysis include: i) when processing the text, the reader must activate diverse intertexts that reflect a complex text modelling entanglement, which resorts to -and undoubtedly challenges- the cultural competence in the receiver; ii) text intersection in the opinion piece becomes a discursive strategy whereby the enunciator subject evaluates both critically and ironically a political event in which power, public opinion and justice are confronted. In summary, the use of these procedures enriches the textuality and genre form of an opinion journalistic text.

Keywords: opinion piece, Biblical discourse, political discourse, intertextuality, reception.

\section{Resumo:}

Este artigo aborda alguns cruzamentos textuais do discurso bíblico e político produzidos no género discursivo jornalístico de opinião 'Coluna', a partir de um fato noticioso e político contingente como o 'Caso Caval', envolvendo a família presidencial chilena, gerando variados sentidos. A metodologia consiste na análise textual de una coluna publicada em um jornal de circulação nacional no Chile, intitulada "O martírio do filho", desde uma perspectiva discursiva e contextual. Entre os resultados obtidos da análise destaca-se: i. o leitor no seu processamento deve ativar diversos intertextos, reflexo de um complexo enredo de configuração textual que apela e desafia, sim dúvida, a competência cultural do sujeito receptor; ii. esse cruzamento de textos presente na coluna, constitui uma estratégia discursiva mediante a qual o sujeito enunciador avalia crítica e ironicamente um fato político onde o poder, a opinião pública e a justiça são confrontados. Em suma, o emprego destes procedimentos enriquece a textualidade e genericidade de um texto jornalístico de opinião.

Palavras-chave: coluna, discurso bíblico, discurso político, intertextualidade, recepção.

Notas de autor:

\footnotetext{
a Autor de correspondencia. Correo electrónico: fpastene@ubiobio.cl
} 


\section{Introducción}

En el contexto de los estudios del discurso (ED), Van Dijk (2009, 2010, 2015) ha planteado una compleja realidad que articula el discurso, ya que este no solo es texto, género, cognición y sociedad, sino también 'acción, contexto, poder e ideología', constituyéndose en macrocategorías analíticas, que al interrelacionarse, pueden permitir acercamientos a los discursos producidos en diferentes dominios sociales y culturales, con la finalidad de comprender su funcionamiento y los mensajes que de ellos se derivan. Para López (2014), el estudio del discurso responde a una pluralidad de enfoques y a una interrelación de disciplinas, pero que, a pesar de las distintas tendencias, coinciden en supuestos básicos que facilitan la descripción y análisis de las prácticas discursivas y la interrelación que existen entre ellas:

El discurso es constitutivamente comunicativo; se trata de una manifestación interactiva, explícita e implícitamente; está siempre contextualizado; se actualiza mediante determinados canales y medios; recurre a variados géneros discursivos y se sirve de textos diferentes según los tipos de voces, planificación, unidades de composición y formas de textualidad (p. 17).

Desde la Escuela Francesa del Análisis del Discurso, Charaudeau (2012) precisa una concepción de la noción de 'discurso' que releva su dimensión significativa: “(...) es una combinación entre un modo de decir y un modo de significar. De esta combinación dinámica nace el discurso como un conjunto de posibles significados que circulan en la sociedad" (p.100).

Por su parte, algunos de los insumos que se desprenden de este rico y vasto ámbito transdisciplinario de los estudios del discurso (ED), esa sido cultivado por varios autores y bajo distintas perspectivas, los mismos son abordados en ámbitos tan relevantes como el educativo, en la medida en que se orientan hacia desarrollo de una lectura analítica y crítica de temas sociales cada vez más complejos, donde los sujetos en formación se ven enfrentados a comprender diferentes textos y a emitir un punto de vista fundamentado. En el año 2015, el Ministerio de Educación de Chile [MINEDUC] (2015b) publicó la actualización del Programa de Estudio de Lenguaje y Comunicación, de $3^{\circ}$ Año de Enseñanza Media, con una nueva Unidad de Aprendizaje, titulada: "LO SOCIAL Y LO POLÍTICO. Comentario y crítica de textos literarios y no literarios”. Específicamente, en las “Orientaciones Didácticas para la Unidad”, se plantea lo siguiente:

La unidad tematiza la vida social y política, y aborda textos que la problematizan. Se trata de observar con mirada crítica la relación entre los individuos, sus ideas, sueños y deseos, y las sociedades que existen. El lenguaje es un medio vinculante entre estos tres conceptos, en la medida en que nos permite representar y construir sueños e ideas, expresar y comunicar nuestros deseos, y establecer vínculos con las comunidades a las que pertenecemos. (...) En el desarrollo de esta unidad, que aborda lo político y social, se deben entregan antecedentes contextuales sobre el tema tratado, que sirvan como insumo para que los y las estudiantes puedan elaborar argumentos cerca de las ideas propuestas en los diferentes textos. Generar instancias de lectura crítica de algunos fragmentos permite a la o el docente desarrollar en los y las estudiantes el pensamiento divergente y la no discriminación ante algunas temáticas que no son fáciles de comprender (políticas, de género, de etnias, entre otras) (MINEDUC, 2015b, p. 79).

Este desafío curricular se dirige hacia el tratamiento de 'lo social y lo político', tomando en cuenta la dimensión del discurso y sobre todo, la consideración de un contexto social y cultural agitado, de confrontación de ideas por los medios y las redes sociales, abarca los diferentes soportes por donde transita hoy la opinión pública. La emergencia de variadas agrupaciones y movimientos sociales, quienes, mediante la palabra y el discurso declaran, anuncian, protestan, exigen y proponen desde el seno de una sociedad libre y democrática. En suma, en el surgimiento de varias problemáticas o asuntos que necesitan atención, procesamiento y mediación para comprenderlos y generar juicios o posturas, son propios de un sujeto situado, pensante, reflexivo y crítico, es decir, de un ciudadano empoderado mediante el lenguaje, siendo esta la meta ideal pedagógica.

Este artículo tiene como objetivo principal demostrar la singular conformación discursiva de una columna, cuyo plan textual interrelaciona el discurso bíblico y el discurso político, mediante la estrategia intertextual 
que obliga al lector activar variados intertextos. El autor, Max Colodro, evalúa crítica e irónicamente un hecho político donde se confronta el poder, la opinión pública y la justicia, como es el 'Caso Caval', que afectó a la familia presidencial chilena, generando una tensión o conflicto filial, social y político, entre la Presidenta Michel Bachelet y su hijo Sebastián Dávalos, protagonista principal de la trama narrativa que configura toda la columna.

\section{Un hecho noticioso/político como punto de partida: "El Caso Caval"}

La situación concreta que origina la escritura de la columna de opinión que será analizada parte del llamado 'Caso Caval', que ha sido difundido y seguido por los medios de comunicación por las implicancioness que ha tenido a nivel político. A continuación, se reseña este hecho. En pleno verano de 2015, período de vacaciones, cuando la Presidenta Michel Bachelet estaba descansando en Caburgua, Región de La Araucanía, los medios informativos entregaban una noticia que iba a generar revuelo nacional e internacional, ya que involucraba en una complicada posición al hijo de la Presidenta de la República, Sebastián Dávalos, quien, a la fecha del escándalo, se desempeñaba como Director Sociocultural de la Presidencia, designado por su propia madre. Al poco tiempo de asumida la primera magistratura de la nación, se origina el Caso Caval. Dávalos junto con su esposa, Natalia Compagnon, forman parte de la Empresa Exportadora y de Gestión Caval Ltda. Esta empresa, a pesar de su bajo patrimonio, logró obtener un crédito del Banco de Chile - una de las instituciones financieras más antiguas e importantes del país - por seis mil quienientos millones de pesos chilenos para comprar 44 hectáreas de terrenos en Machalí, comuna ubicada al sur de la capital de Santiago de Chile, que luego fueron vendidas a terceros por nueve mil quinientos millones. Esta operación generó una ganancia de aproximadamente dos mil quinientos millones, y de paso se pagó el crédito solicitado más los intereses de una sola vez. El escándalo que provocó este hecho consistió en cuestionar cómo una pyme, de bajo patrimonio, logró un crédito tan elevado. Se acusó a Sebastián Dávalos, de que valiéndose de su posición política, empleó información privilegiada que le permitió acceder a este crédito, lo cual en Chile se sanciona con multas. Esta situación, que en el ámbito financiero puede darse, no habría causado tanta conmoción pública, si no se tratara de la familia directa de la Presidenta de la República: su hijo mayor y su nuera; más aún, si Dávalos ocupaba, al mismo tiempo de develarse los hechos, un cargo político de absoluta confianza como es el que han desempeñado las ex primeras damas. Esta noticia surgió en un contexto nacional 'muy sensible' con el medio político, por la desconfianza que la ciudadanía tiene sobre este sector, acentuado por los casos de corrupción y operaciones políticas tildadas de deshonestas e ilícitas, que dañan la confianza y la credibilidad en las instituciones del Estado. A los pocos días, Sebastián Dávalos tuvo que dejar su cargo (Cf. Godoy, 2015, en línea).

\section{El texto en estudio: La columna de opinión}

El caso escogido para el análisis es una columna de opinión, cuyo título es "El martirio del hijo" de Max Colodro $^{1}$, publicada el domingo 7 de junio de 2015 en el diario La Tercera (p. 11) de la Sección de Política. La columna está conformada por cinco párrafos y, en promedio, cinco enunciados por párrafo. Su autor, Max Colodro, es Sociólogo, Doctor en Filosofía y analista político, director del Magíster en Comunicación Política en la U. Adolfo Ibáñez y columnista del diario La Tercera. También, el autor posee un blog del mismo diario La Tercera, denominado De menos a Max (Colodro, 2015a), donde se pueden visualizar los comentarios que originó su escrito. Al respecto, se lee: “¿Un giro a la ficción?, malito el texto". "De cuál se fumó Don Max. Muchas veces aplaudimos sus certeros análisis, pero hoy nos fuimos patinó la moto (sic)". "Se entiende el conato de columna, pero es delirante. Tómate un ansiolítico mejor". "Fantástico comentario, lamentablemente el editor confundió la foto”. 
Estas opiniones revelan, sin duda, que, junto con el tema tratado, la forma cómo el autor abordó la estructura textual, retórica y estilística de su columna de opinión rompió con las expectativas de sus lectores; tal vez, ellos no comprendieron el artificio o estrategia de composición empleados, dados a una lectura más directa, más denotativa y sin excesivas alusiones o conexiones intertextuales, que demandan del lectora/a un mayor detenimiento y procesamiento de la información. Es un texto elaborado con sutileza escritural y sofisticación intelectual, que nos hace pensar que puede ir dirigido a un tipo de lector más específico, al político.

Para Adam y Heidmann (2004), el efecto de textualidad es inseparable del efecto de genericidad, es decir, el texto escogido constituye un ejemplar que remite a un modelo mayor genérico como es la columna de opinión, un texto periodístico de opinión. De lo cual se desprende que el autor, al escribir un texto concreto, posee este modelo genérico, pero al mismo tiempo, puede generar variantes del mismo o 'jugar' con este esquema, innovando con aquella tradición propósitos de recepción definidos, lo que lleva a Parodi (2008) a expresar que:

El género (discursivo) constituye una constelación de potencialidades de convenciones discursivas, sustentada por los conocimientos previos de los hablantes/escritores y oyentes/lectores (almacenados en la memoria de cada sujeto), a partir de constricciones y parámetros contextuales, sociales y cognitivos. (...) pues no son entidades de modo estático, sino altamente dinámicas (p. 26).

Esta plasticidad del género discursivo lleva aparejado, entonces, las distintas posibilidades de escritura que se pueden encontrar en un texto concreto. Desde el punto de vista genérico, la columna es un texto periodístico de opinión llamado también comentario:

El comentario (o columna) es un artículo razonador, orientador, analítico, enjuiciativo, valorativo -según los casos- con una finalidad idéntica a la del editorial. Se diferencia básicamente en el comentario que es un artículo firmado y su responsabilidad se liga tan sólo al autor del trabajo (Martínez, 1997, p.372).

La columna de opinión forma parte del periodismo de opinión, texto que es desarrollado en la línea de la argumentación con razones probatorias, de carácter persuasivo y puntos de vista eminentemente personales y que aparecen firmados por un columnista de prestigio profesional. Sin embargo, una clave o función adicional del texto es que:

(...) lo propio del comentario - columna- es el vaticinio más o menos profético acerca del ulterior desarrollo de los acontecimientos. Diríamos que el editorialista adopta posiciones ideológicas con vigencia actual, mientras que el comentarista —o columnista - emite juicios para entender el futuro de los hechos (Martínez, 1997, p. 373).

No deja de tener razón Martínez (1997) al asignar un rasgo vaticinador a la columna, que se acentúa en este texto periodístico, cuando se tratan temas políticos, ya que la política se destaca por una proyección utópica, de ideas, sueños y proyectos a realizar, cautivando voluntades; la política tiene esa dimensión de futuro.

\section{Hipotextos en el hipertexto: conexiones textuales del discurso bíblico y el discurso político}

Uno de los componentes claves en la configuración del discurso es la intertextualidad, que, para Beaugrande y Dressler (1997), constituye una norma de textualidad la cual se debe tener en cuenta a la hora del procesamiento de los textos: "la intertextualidad se refiere a los factores que hacen depender la utilización adecuada de un texto del conocimiento que se tenga de otros textos anteriores" (Beaugrande y Dressler, 1997, p. 45). Los mismos autores señalan que, para acceder a una interpretación competente como estrategia, se debe recurrir al conocimiento del texto anterior y de la intención que lo produjo; esta aprehensión incrementaría, por tanto, la atención y la informatividad del texto. 
En efecto, activar estos recursos textuales es lo que se requiere para acceder a una lectura analítica y crítica de la columna "El martirio del hijo" de Max Colodro (2015b), donde, principalmente, cumplen una función clave las relaciones o cruces entre el discurso bíblico y el político, a partir de la contingencia noticiosa actual del "Caso Caval".

Pero, antes, precisemos las nociones de discurso político, discurso bíblico y cruce textual que se manejan en este estudio. Van Dijk (2009) plantea desde un principio que el término 'discurso' es polisémico, aunque nos interesa esta visión:

Así, cuando caracterizamos el discurso como un suceso de comunicación, hablamos del discurso en general. De manera similar, aunque algo distinta, podemos hablar en general de tipos específicos o dominios sociales del uso del lenguaje y el discurso, por ejemplo, cuando utilizamos las expresiones discurso médico o discurso político” ( p. 17).

Por lo tanto, el discurso político encierra los textos producidos por un ámbito como es la política y que incluye, por cierto, otros elementos. Para Van Dijk y Mendizábal (1999), el discurso político es aquel realizado por los actores políticos, es decir, los sujetos de la política, como presidentes, ministros, diputados, etc. Sin embargo, se adiciona otra dimensión: que la política no solamente son los actores oficialmente designados, electos para hacer política, sino también lo hacen sectores de la sociedad de diversa índole como los trabajadores, los campesinos, los estudiantes, las "masas" y el margen de actores, autores y participantes políticos se amplia aún más. Finalmente, los autores plantean que el discurso político se define desde el "actuar político" ubicado en un contexto donde las prácticas o sucesos persiguen finalidades, metas o funciones primariamente políticas. Por su parte, Charaudeau (2011) precisa que el discurso político no tiene sentido fuera de la acción, y que en la acción se juega, para el sujeto político, el ejercicio de un poder.

En cambio, el discurso bíblico se relaciona con la noción de tipo específico de discurso porque involucra precisamente referirse al texto bíblico, a la Biblia como texto sagrado, empleado por las religiones cristianas. Para la RAE (2014), la Biblia es el "Libro sagrado del cristianismo, que comprende el Antiguo y el Nuevo Testamento”. Desde la perspectiva semiótica, Geninasca $(1997,1998)$ específica que el discurso bíblico es un discurso intransitivo - o reflexivo-, porque su función no es tanto informar sobre un objeto o sobre un estado de las cosas - discurso transitivo-, sino que su estructura figurativa y temática apuntan al surgimiento de las condiciones mismas del significado, presuponiendo, en la toma del significado, una racionalidad 'semántica' particular.

Ahora bien, para delimitar qué se entiende por 'cruce textual' es necesario señalar que esta denominación se extrae desde la semiótica, a partir del término 'intertextualidad'. Al respecto, Genette (1989) lo define como: "una relación de copresencia entre dos o más textos, es decir, eidéticamente y frecuentemente, como la presencia efectiva de un texto en otro" (p. 9). De este modo, 'cruce textual' se define como un procedimiento que involucra la presencia e interrelación de textos o discursos diferentes en un texto concreto, como, por ejemplo, en la columna analizada se observa la inclusión de participantes, temáticas, contextos y otros elementos provenientes del discurso bíblico y del discurso político, principalmente.

Un primer mecanismo del trayecto de la lectura que se activa con la decodificación del título "El martirio del hijo" es el intertexto lector, noción que surge también desde la intertextualidad. A juicio de Mendoza (2008), este concepto consigue uno de los efectos más atractivos de la recepción lectora, que es precisamente la identificación de claves y recursos discursivos, formales, temáticos o de intencionalidad del texto. Estos reconocimientos se dan en la confluencia del intertexto de la obra y del intertexto personal del lector, es decir, en la lectura. En un texto concreto se evocan uno o varios hipotextos. Para Genette (1989) el hipotexto es un texto que se puede identificar como la fuente principal de significado de un segundo texto, al que se le denomina hipertexto. El intertexto lector señala y reconoce las conexiones que hay entre referentes aludidos, citados, reelaborados, manipulados...- del texto. El receptor los identifica mediante la activación de su intertexto lector, que aporta los conocimientos - previos - procedentes de la experiencia y del estudio 
o aprendizaje. De esta manera, identificando la referencia textual, el lector puede matizar la intencionalidad que se propone el nuevo texto - hipertexto-.

A partir de la lectura del título de la columna, se generan expectativas e inferencias predictivas referentes a cómo es su contenido, dependiendo del grado de competencia cultural o enciclopédica ${ }^{2}$ que posea el lector, conectando, por ejemplo, con la esfera religiosa, con el discurso bíblico. Las acepciones de 'martirio' en el "Diccionario de la Lengua Española” (RAE, 2014, p. 250) son: "1. Muerte o tormentos padecidos por causa de una religión, unos ideales, etc. 2. Dolor o sufrimiento, físico o moral, de gran intensidad. 3. Trabajo largo y muy penoso." Entonces, las preguntas que surgen de este avance lector pueden ser: ¿De qué hijo estamos hablando? ¿Cuál es su filiación? ¿Cómo es este martirio? ¿Cuál es el dolor o sufrimiento, físico o moral, que padece? ¿A qué se debe este padecimiento? Y para el análisis: ¿En qué medida se relaciona un hecho actual y contingente con lo bíblico? ¿Cuáles son las conexiones que se pueden generar entre el discurso político y el discurso bíblico? ¿Qué hipotextos se pueden identificar en el hipertexto y sus sentidos?

Cabe recordar lo que Genette (1989) ha planteado respecto a cómo un texto B parte de otro A. Es decir, el texto que se puede identificar como la fuente principal de significado, le llama hipotexto (texto A) y al posterior o al que integra estas fuentes iniciales le denomina hipertexto (texto B). Entonces, la columna que analizaremos es el hipertexto y que se ha construido sobre la base de un esquema narrativo que considera distintos relatos o situaciones ejemplares del texto bíblico — siendo este el hipotexto-, engarzándolos con la situación que actualmente viven los dos sujetos del enunciado: El hijo - Sebastián Dávalos, hijo de la Presidenta M. Bachelet-y la Madre - Presidenta M. Bachelet-, dos figuras políticas.

Para una mejor exposición y respuesta de los interrogantes planteados, se presentan, primero, cada uno de los párrafos, adicionándoles un subtítulo con el subtema clave, que puede orientar la lectura, seguido de los análisis y comentarios respectivos.

Párrafo $1=$ "El destino"

Como un destino bíblico, el hijo puesto a prueba en nombre de la madre. Tras ser forzado al destierro y a la travesía por el desierto, debe encarar ahora la prueba de la lealtad filial escribiendo los salmos de su propia inmolación. Acto sacrificial de connotaciones mesiánicas, buscando preservar a la eterna Inmaculada para el gran Juicio Final. Vocación Salvífica todavía incierta o en compás de espera, pero que ya llena las calles de un saludable aroma a incienso. (Colodro, 2015, p. 11)

En este primer párrafo, se presentan los dos sujetos del enunciado - hijo y madre- implicados, ahora, mediante la reactivación de esquemas narrativos previos o de acontecimientos bíblicos, tales como la alusión a la Tentación de Cristo (Jesús) presente en los Evangelios, y que constituye el hipotexto bíblico 1, registrado en Mateo 4:1-11; Marcos 1:12-13; Lucas 4:1-1 (Cf. La Sagrada Biblia, 1968). Se recordará que la figura bíblica es conducida al desierto por el Espíritu de Dios para ser tentada por el diablo, justamente, puesto a pruebas que Cristo las embiste, refutándolas con citas de las propias Sagradas Escrituras, venciendo al demonio. Se inicia lo que constituiría un proyecto o tránsito hacia la purificación, la salvación, con la puesta en acción de una cierta prueba de fidelidad a su madre: de protección y salvación, al mismo tiempo, hacia ella, manteniéndola sin mancha o culpabilidad. Está en un proceso de penitencia, latente, pero de gran significado moral. En este párrafo se inscribe la situación inicial de un desiderátum, un proyecto inicial, de un "vivo y constante deseo". El hijo tiene una misión que debe cumplir. Entonces, ¿cuál es la prueba?

Párrafo 2 = "El deber"

El hijo debe prosternarse hasta confirmar la absoluta desvinculación de la madre de toda huella de pecado. Debe asumir su culpa plena, por acción y omisión, engaño y ocultamiento. La inocencia materna debe quedar herida y expuesta por la traición, por la deslealtad de quien no fue capaz de resistir el yugo de las tentaciones. El hijo y sus cómplices, acólitos todos ellos de una ambición sin límite que, como en Judas, los condujo a vender su dignidad por un saco de monedas. Las llamas purificadoras los esperan impacientes y no podría haber en este rito nada más que la reparadora tranquilidad de lo consumado. (Colodro, 2015, p. 11)

En este segundo párrafo, se refuerza la modalidad deóntica del 'deber ser' del sujeto del enunciado, el hijo, ya declarado en el párrafo anterior, donde es expresanda explícitamente la misión que debe ejecutar en este 
trayecto o proceso: exculpar a la Presidenta de la República de cualquier vínculo con el 'Caso Caval', y este acto de desvinculación implica ciertamente el acto sacrificial: inculparse plenamente. La madre Presidenta autoridad- es inocente; él es el culpable, quien cometió un acto de traición no solo filial, sino político, lo que conllevó consecuencias negativas para la figura presidencial y el Gobierno. El sujeto de la enunciación reactiva ahora explícitamente un hipotexto bíblico 2, que es la Traición de Judas contra Cristo ("Judas ofrece entregar a Jesús" en Mateo 26: 14-16; Marcos 14:10-11; Lucas 22:3-6), con la finalidad de enfatizar este acto ignominioso, que no solo fue individual, sino con el concurso de otras personas como su esposa y asesores como lo denuncian los textos informativos sobre el Caso Caval, realizando un negocio que habría vulnerado las leyes y generado, de paso, desconfianza en el mercado; sujetos amorales que no midieron las consecuencias y que deben ser sancionados por el yerro.

Párrafo 3= "El silencio"

Pero el hijo se oculta aún entre las sombras, imponiendo temor y duda entre los fieles. ¿ Será lo suficientemente fuerte y digno para morir solitario en la cruz? ¿Tendrá el temple de esos pocos y genuinamente puros que son capaces de llevarse su verdad hasta la tumba? Nadie lo sabe, el silencio y la penumbra mantienen a todos en desvelo, especialmente a Ella que espera no ser, como ya ocurrió una vez, defraudada por su sangre. Ahora, sin embargo, el anhelo está puesto en la altivez del espíritu, en la gentil misericordia de un hijo que finalmente entiende cuál es su verdadera misión en este mundo. (Colodro, 2015, p. 11)

En este tercer párrafo, el conector discursivo adversativo con el cual comienza el enunciado - pero-) contrapone cierto el proyecto deseado, el que no se ha concretado con este 'acto sacrificial', de inmolarse, de ser héroe, mártir, activándose el hipotexto bíblico 3: "Crucifixión de Cristo" ("Crucifixión y muerte de Jesús" en Mateo: 27:32-56; Marcos 15: 21-41; Lucas 23:26-49; Juan 19:17-30). Esta incertidumbre inquieta a los correligionarios y a la clase política dirigente. Con las interrogantes retóricas desplegadas, se insinúa que el actante principal - hijo- debe mejor callar, silenciarse, y los políticos partidarios —es decir, el círculo de poder - esperan que no cometa una nueva falta. La primera fue la de acompañar a su esposa a la entrevista con Andrónico Luksic, dueño del Banco Chile, para solicitar el crédito a espaladas, supuestamente, de su madre. Ahora, todos despliegan la estrategia del 'silencio'. La verdadera misión: callar, no denunciar, impulsar un pacto de silencio, donde el principal acusado debe inmolarse políticamente.

Charaudeau (2011), en su artículo "Le discours politique ou le pouvoir du langage", plantea que el sujeto político, cuando se encuentra en situación de enunciación, emplea diversas estrategias discursivas esté o no en el poder. Una de ella es la "parole de dissimulation”. Esta estrategia de disimulación ${ }^{3}$ es otro aspecto intrínseco al discurso político, el actor político no dice nunca cualquier cosa. Él sabe que debe prever tres cosas: las críticas de sus adversarios, los efectos perversos de la información mediática y los movimientos sociales que él debe intentar de neutralizar su avance. Se instala, entonces, un juego de enmascaramiento entre el discurso - habla - pensamiento y acción, que conduce a Charaudeau (2011) a examinar la cuestión de la mentira — mensonge - en la política. Todo hombre - sujeto- político sabe que le es imposible decir todo, en todo momento, y decir las cosas exactamente cómo él las piensa o las realiza. Entre las subestrategias, se encuentra la 'estrategia del silencio', es decir, la ausencia de declaración.

Sin embargo, este 'silencio' (estrategia) genera una fricción, una transgresión, por cuanto aquí se emplea para proteger, supuestamente, "a las personas de sus enredos o intrigas delictuosas" (Charaudeau, 2014, p. 6), y no se trata de un 'engaño necesario', donde efectivamente debe ser empleado para servir al Bien Común (Charaudeau, 2014). Entonces, la estrategia del silencio posee discursiva y políticamente una función ideal, pero que, en el caso analizado, se emplea con una función estratégica: mantener la credibilidad de la figura presidencial que tiene el poder político, es decir, su ethos. Según Charaudeau (2011), la credibilidad es una obligación (o condición necesaria) del discurso político, y, específicamente, el sujeto político debe mantener un 'ethos de virtud'. En este sentido, los hechos acaecidos y enfatizados mediáticamente han mermado la credibilidad de los actores políticos. 
Párrafo $4=$ "La espera"

La espera es dura; no hay signos divinos que permitan anticipar si el hijo honrará su destino de mártir o se dejará llevar por la segunda traición de entregar a la madre. No ha querido decir palabra o mostrar su rostro, lo que puede ser un buen o mal augurio. En su refugio, sometido están ahora a las presiones de ángeles y demonios, que lo acechan día y noche buscando convencerlo de seguir uno u otro camino. Nosotros, mientras tanto, simplemente rezamos, para que la madre pueda seguir conservando y luciendo su aura de indudable santidad. (Colodro, 2015, p. 11)

En este cuarto párrafo, el autor se aparta un poco de la alusión bíblica, aunque con la manteniendo ciertos signos. Retorna a la realidad directa y concreta, anunciando un supuesto conflicto interior que sufriría el protagonista, pero focalizando su atención en la reiteración de la estrategia central ya develada en el texto anterior, y adoptada por Dávalos, como es el silencio. Aunque supuestamente dubitativo por la opción de un camino u otro, se mantiene la disimulación obligada para conservar el poder, la legitimidad, el estatus, la credibilidad y la estatura moral de la primera autoridad política del país. Luego, la voz autorial se personaliza, pluralizándose en el pronombre personal 'nosotros', intentando empatizar, con un tono irónico, con un sector de los ciudadanos o, quizás, todos, que a estas alturas no creerían totalmente en la inocencia de la mandataria.

Párrafo 5= "La incredulidad"

Quedan días o quizás sólo horas; la venida del hijo está cerca y los corazones se agitan con soberana inquietud. ¿Reconoceremos su rostro? ¿Será como el de entonces o ya no será el mismo? Qué enigma entre las aguas el que nos somete a esta espera de penitencia y ayuno. Protégenos Dios Padre y que sea Tu Voluntad. Tuyo es el reino de los pobres de espíritu que alguna vez creyeron y anhelaron la Verdad. (Colodro, 2015, p. 11)

En este quinto y último párrafo, se concluye con este trayecto iniciado con las alusiones al discurso bíblico, donde, finalmente, la ironía se impone abiertamente en esta espera impaciente, que hace declarar al autor su incredulidad de que se cumpla el deber-ser, y cuya proposición es interpretada en los siguientes términos (tesis implícita): el hijo no entregará a su madre para 'salvarla' políticamente y tratando de que en el poder, no melle su credibilidad y legitimidad, mediante la estrategia discursiva política del silencio.

Por último, es significativo que en este último segmento textual aparezcan los matices de vaticinio o de proyección futura de los acontecimientos de la columna como género, evidenciada en las interrogantes retóricas, con detonante ironía. El ejemplar analizado se ha configurado con una trama narrativa, pero que mantiene la orientación argumentativa de la columna, cuyos dos modos de razonamiento bien desplegados han sido, por un lado, la analogía, al compararse la situación que viven los protagonistas políticos con episodios bíblicos del Evangelio de la vida del mismísimo Jesús, hiperbolizándola justamente con otro modo o recurso como es la ironía. Para Perelman y Olbrechts-Tyteca $(2006){ }^{4}$, la ironía es una técnica argumentativa que posee una finalidad pragmática y que forma parte del contexto de lo cómico en la argumentación, debido a que lo que mueve a la risa puede servir para: "afirmar una comunión entre orador y auditorio -o columnista y lector $^{5}$-, para efectuar devaluaciones, sobre todo, para ridiculizar al adversario para operar los entretenimientos oportunos" (Perelman y Olbrechts-Tyteca, 2006, p. 297).

La función pragmática de la ironía consiste en un señalamiento evaluativo, casi siempre peyorativo. La burla irónica se presenta generalmente bajo la forma de expresiones elogiosas que implican, al contrario, un juicio negativo (Hutcheon, 1981). La ironía es la que permite que el discurso muestre efectivamente la verdad que encierra (...). Por ello, el recurso irónico significa una huida de toda sabiduría de escuela, de toda pretensión de sistema y tiene un propósito liberador (Disselkoen, 2003).

\section{Conclusiones}

El lector debe activar diversos intertextos para construir el significado de esta columna, principalmente, los provenientes del discurso bíblico en directa conexión con el discurso político, donde se ponen en escena dos principales actores políticos: La Presidenta Michel Bachelet y su Hijo Sebastián Dávalos, en una relación de tensión no solo filial, sino, sobre todo, política, surgida del 'Caso Caval. Esta vinculación con lo bíblico es una 
estrategia discursiva, que tratada con los mecanismos de hiperbolización e ironía, el autor desea acentuar el conflicto con una sanción moral y social, en un contexto nacional donde la actividad política está cuestionada y escrutada cotidianamente por los medios y soportes de comunicación, de un ciudadano cada vez más atento y crítico.

El columnista aprovecha estratégicamente las posibilidades retóricas y textuales que le brinda la flexibilidad del género discursivo para generar una innovación textual como se observa en la columna de opinión analizada. Surge un complejo e interesante entramado de configuración textual el cual sin duda apela y desafía la competencia cultural del sujeto receptor, cuyos conocimientos y experiencias previas sobre el asunto tratado y la organización discursiva del escrito son claves para el adecuado procesamiento de la información.

Además, y mediante las entre líneas del texto analizado, el sujeto enunciador evalúa crítica e irónicamente un hecho político donde se confronta el poder, la opinión pública y los deseos de justicia (moral, divina, humana). La utilización de la ironía no solo como embellecimiento, ornatum, sino como un procedimiento comunicativo que cumple en la argumentación una función intensificadora de ciertos argumentos, los focaliza con el objetivo de obtener mejores resultados en la persuasión. En este sentido, la ironía presenta una propiedad fuertemente argumentativa porque condensa, generalmente, "una argumentación indirecta dado que quiere hacer entender lo contrario de lo que se dice, suponiendo conocimientos adicionales sobre hechos, personas o valores" (Pérez y Vega, 2003, p. 55). Para el enunciador, en suma, la ironía constituye una estrategia discursiva orientada hacia la eficacia de la argumentación, ya que pretende lograr la aprobación del destinatario al punto de vista que se presenta para su validación.

En el texto analizado, se destaca la presencia de la estrategia discursiva política del silencio, revelándose como un oportuno, pero cuestionado recurso, que el sujeto de la enunciación (Sebastián Dávalos) y sus cercanos emplean para la supuesta protección del ethos de virtud, de la credibilidad y legitimidad de la figura presidencial y, de paso, su gobierno. Esta situación pone de relieve las estrategias de disimulación, entre otras, que usa el sujeto político en su afán por ostentar y defender su poder, como además persuadir o sobrellevar el malestar político y social que expresa la opinión pública.

El análisis realizado puede constituirse en un aporte pedagógico para tratar en el aula la: Unidad de Aprendizaje sobre 'Lo social y lo político' y Comentario y crítica de textos literarios y no literarios, de la asignatura de Lenguaje y Comunicación, tal como se plantea en el Programa de Estudio de Tercer Año Medio del Ministerio de Educación de Chile, mediante los insumos que brindan los estudios del discurso. Es la primera vez que en un instrumento curricular del área de lengua, aparece, de modo directo, enunciada esta temática más sociológica, ya que tradicionalmente, mediante el enfoque lingüístico-gramatical y filológico, el centro estaba orientado hacia un análisis más estructural del texto literario. Sin embargo, en la actualidad es el enfoque comunicativo y cultural el que funda las orientaciones didácticas (MINEDUC, 2015a). Adicionalmente, esta propuesta ministerial es un síntoma del debate actual que existe en nuestro país por incluir, poco a poco en el currículum nacional, la temática de la 'formación ciudadana'.

Referente al discurso bíblico, que es uno de los hipotextos desplegados estratégicamente en la columna analizada, se ha realizado una aproximación a su funcionamiento en el discurso. Es necesario constatar que posterior a este estudio, según Maingueneau (2009), existe un escaso tratamiento y/o surgimiento de un análisis del discurso religioso/bíblico, debido, entre otras razones, a que su acercamiento es como texto literario o texto filosófico, con gran influjo de la hermenéutica, o bien, que los creyentes y los expertos de las religiones no se van a interesar por aproximaciones que ignoran la dimensión espiritual de los textos.

Por último, con la finalidad de profundizar en el estudio del texto escrutado, se podría generar un modelo de configuración textual donde se delimiten o integren otros hipotextos a los ya vistos, como el relato o texto policial, que considera como rasgo principal la resolución de un enigma por parte de un héroe según el esquema canónico, y el texto jurídico junto con las implicancias que rodea un caso policial. 


\section{Agradecimientos}

Origen del artículo: El artículo es producto de un trabajo pedagógico para la cátedra de Análisis del Discurso, dictada en la carrera de Pedagogía en Castellano y Comunicación en la Universidad del Bío-Bío, Chile, y que se adscribe a las líneas de investigación del Grupo de Investigación LEA-UBB. Asimismo, una versión de este escrito fue presentada como ponencia en el IX Encuentro Nacional de Estudios del Discurso, del Capítulo Chileno de la Asociación Latinoamericana de Estudios del Discurso (ALED), realizado en la Universidad Católica de Temuco, Temuco, noviembre de 2016.

\section{Referencias}

Adam, J. \& Heidmann, U. (2004). Des genres à la généricité. L'exemple des contes (Perrault et les Grimm). Langages, 153(1), 62-72. https://doi.org/10.3917/lang.153.0062

Beaugrande, R. \& Dressler, W. (1997). Introducción a la lingüistica del texto. Barcelona: Ariel.

Colodro, M. (2015a). "De menos a Max" [en línea], disponible en: http://voces.latercera.com/autor/max-colodro/, recuperado: 14 de enero de 2017.

Colodro, M. (7 de junio de 2015b). El martirio del hijo. La Tercera. Santiago.

Charaudeau, P. (2011). Le discours politique ou le pouvoir du langage. Paris: Université de Paris 13. Recuperé de http://www.youscribe.com/catalogue/rapports-et-theses/savoirs/sciences-humaines-et-sociales/le-discourspolitique-ou-le-pouvoir-du-langage-304525, recuperado: 10 de enero de 2017.

Charaudeau, P. (2012). Entre la pragmática y las teorías de la enunciación. Entrevista a Patrick Charaudeau. En O. Londoño, Poliedros discursivos. Miradas a los Estudios del Discurso (pp. 97-106). Villa María: Eduvim.

Charaudeau, P. (2014). "L'art de mentir en politique". Sciences Humaines 256 [Recuperé janvier 5, 2017 de http://ww w.patrick-charaudeau.com/IMG/pdf/L_art_de_mentir_en_politique.pdf

Disselkoen, H.R.O. (2003). Razón e ironía. Revista philosophica, 26, 181-194.

Genette, G. (1989). Palimpsestos: la literatura en segundo grado. Madrid: Taurus.

Geninasca, J. (1997). La Parole littéraire. Paris: Presses Universitaires de France.

Geninasca, J. (1998). Le Discours n'est pas toujours ce que l'on croit, Protée, 26(1), 109-118. Recuperado de http://w ww.uqac.ca/protee/pages/numero/26-1.htm\#10

Godoy, M. (2015, febrero 16). El caso Caval explicado con manzanitas. Economía para todos Con manzanitas. Recuperado de https://economiatodos.cl/2015/02/16/la-gravedad-del-caso-davalos-caso-nueragate/

Hutcheon, L. (1981). Ironie, Satire, Parodie: une approche pragmatique de l'ironie. Poetique, 140-155. Recuperado de https://tspace.library.utoronto.ca/bitstream/1807/10253/1/TSpace0166.pdf

La Sagrada Biblia. (1968). Chicago: The Catholic Press.

López, C. (2014). Análisis del discurso. Madrid: Síntesis.

Luchetti, E. (2008. Didáctica de la Lengua. Buenos Aires: Bonum.

Maingueneau, D. (2009). Introduction. La difficile émergence d'une analyse du discours religieux. Langage et sociéte, 130(4), 5-13. https://doi.org/10.3917/ls.130.0005.

Maquiavelo, N. (2009). El principe. Barcelona: Brontes.

Martínez, J. (1997). Curso general de redacción periodística. Madrid: Paraninfo.

Mendoza, A. (coord.). (2008). Textos entre textos. Las conexiones textuales en la formación del lector. Barcelona: Horsori.

MINEDUC. (2015a). Bases Curriculares. Lengua y Literatura. Santiago: Unidad de Currículum y Evaluación.

MINEDUC. (2015b). Programa de Estudio de Lenguaje y Comunicación, de $3^{\circ}$ Año de Enseñanza Media. Santiago: Unidad de Currículum y Evaluación.

Parodi, G. (ed.). (2008). Géneros académicos y géneros profesionales: Accesos discursivos para saber y hacer. Valparaíso: Ediciones Universitarias de Valparaíso. 
Perelman, Ch. \& Olbrechts-Tyteca, L. (2006). Tratado de la argumentación. La nueva retórica. Madrid: Gredos.

Pérez, M. \& Vega, O. (2003). Técnicas argumentativas. Santiago: Ediciones Universidad Católica de Chile.

Real Academia Española [RAE]. (2014). Diccionario de la lengua Española (DEL). Madrid: Espasa.

Van Dijk, T.; Mendizábal, I. (1999). Análisis del discurso social y politico. Quito: ABYA-YALA.

Van Dijk, T. (2009). El discurso como estructura y proceso. Barcelona: Gedisa.

Van Dijk, T. (2010). El discurso como interacción social. Barcelona: Gedisa.

Van Dijk, T. (2015). Cincuenta años de estudios del discurso. Discurso \& Sociedad, 9(1-2), 15-32. Recuperado de htt p://www.dissoc.org/ediciones/v09n01-2/DS9(1-2)VanDijk.pdf

\section{Notas}

1 En su blog, aparece presentada una reseña biografía sui generis: Filósofo en formación, obrero de la metafísica y coleccionista de dudas. Nació en Santiago una tarde de verano pero casi siempre le llueve sobre mojado. Ex Director de Estudios del Ministerio Secretaría General de la presidencia y ex Vicepresidente de la Comisión Nacional UNESCOChile. Autor de varios libros de filosofía que nadie perdería su tiempo en hojear. Actualmente es Presidente honorario del Club de los Corazones Rotos. Romántico viajero y, a partir de los 30, compañero inseparable del insomnio (Colodro, 2015).

2 Según Luchetti (2008, p. 52) "la competencia cultural o enciclopédica es una competencia básica que le permite al lector comprender un texto. Corresponde a los conocimientos previos o conocimientos del mundo que le permiten hacer predicciones, inferencias, comprender referencias y develar ambigüedades".

3 Sobre este punto, Charaudeau (2011) alude a Maquiavelo, para quien El Príncipe debe ser "un gran simulador y disimulador" (2009, p. 106). Precisamente, Maquiavelo (2009) en el Capítulo XVIII "De qué modo deben guardar los príncipes la fe prometida", afirma: "pero es menester saber encubrir ese proceder artificioso y ser hábil en disimular y en fingir" (pp. 106-107).

4 Los autores generan su teoría de la argumentación desde la Neorretórica.

$5 \quad$ La expresión intercalada es nuestra.

* $\quad$ Artículo de reflexión.

\section{Licencia Creative Commons CC BY 4.0}

Cómo citar el artículo: Pastene-Labrin, F. (2018). Cruces textuales del discurso bíblico y el discurso político en el género columna: claves para su procesamiento. Signo y Pensamiento, 37(72), 34-44. https://doi.org/10.11144/Javerianasyp37-72.ctdb 